\title{
Assembly of functional diversity in an oceanic island flora
}

3 Martha Paola Barajas-Barbosa*1,2,3, Dylan Craven ${ }^{4}$, Patrick Weigelt ${ }^{1,5}$, Pierre Denelle ${ }^{1}$, Rüdiger

4 Otto $^{6}$, Sandra Díaz $^{7}$, Jonathan Price ${ }^{8}$, José María Fernández-Palacios ${ }^{9}$ and Holger Kreft ${ }^{1,10}$

\section{Affiliations}

$7 \quad{ }^{1}$ Biodiversity, Macroecology \& Biogeography, University of Göttingen, Göttingen, Germany.

$8{ }^{2}$ German Centre for Integrative Biodiversity Research (iDiv) Halle-Jena-Leipzig, Germany.

$9{ }^{3}$ Department of Computer Science, Martin Luther University Halle-Wittenberg, Germany.

$10{ }^{4}$ Centro de Modelación y Monitoreo de Ecosistemas, Universidad Mayor, Santiago, Chile.

115 Campus-Institute Data Science, Göttingen, Germany.

$12{ }^{6}$ Island Ecology and Biogeography Research Group, Department of Botany, Ecology and Plant

13 Physiology, Universidad de La Laguna, 38200 La Laguna, Canary Islands, Spain.

$14{ }^{7}$ Instituto Multidisciplinario de Biología Vegetal (IMBIV), Consejo Nacional de Investigaciones

15 Científicas y Técnicas and Facultad de Ciencias Exactas, Físicas y Naturales, Universidad

16 Nacional de Córdoba, Casilla de Correo 495, 5000 Córdoba, Argentina.

$17{ }^{8}$ Department of Geography and Environmental Science, University of Hawai'i at Hilo, Hawaii.

$18{ }^{9}$ Island Ecology and Biogeography Group, Instituto Universitario de Enfermedades Tropicales y

19 Salud Pública de Canarias (IUETSPC), Universidad de La Laguna (ULL), 38200 La Laguna,

20 Canary Islands, Spain.

$21{ }^{10}$ Centre of Biodiversity and Sustainable Land Use (CBL), University of Göttingen, Germany. 
bioRxiv preprint doi: https://doi.org/10.1101/2022.03.04.482684; this version posted March 5, 2022. The copyright holder for this preprint (which was not certified by peer review) is the author/funder, who has granted bioRxiv a license to display the preprint in perpetuity. It is made available under aCC-BY-NC 4.0 International license.

23 Key words: oceanic islands, functional diversity, trait syndromes, functional trait space, plant

24 community assembly.

25 
28 Oceanic island floras are well-known for their morphological peculiarities and exhibit

29 striking examples of trait evolution ${ }^{1,2}$. These morphological shifts are commonly attributed

30 to insularity and thought to be shaped by biogeographical processes and evolutionary

31 histories of oceanic islands ${ }^{1,3}$. However, the mechanisms through which biogeography and

32 evolution have shaped the distribution and diversity of plant functional traits remain

33 unclear. Here, we describe the functional trait space of an oceanic island flora (Tenerife,

34 Canary Islands, Spain) using extensive field and laboratory measurements, and relate it to

35 global trade-offs in ecological strategies. We find that the island trait space is concentrated

36 around a functional hotspot dominated by shrubs with a conservative life-history strategy.

37 By dividing the island flora into species groups with distinct biogeographical distributions

38 and diversification histories, our results reveal that long-distance dispersal, and the

39 interplay between inter-island dispersal and archipelago-level speciation processes drive

40 functional divergence and expand trait space. Conversely, speciation via cladogenesis has

41 overall led to functional convergence, densely packing trait space around shrubbiness. Our

42 approach combines ecology, biogeography and evolution and opens avenues for new trait-

43 based insights into how dispersal and speciation shape the assembly of native island floras. 
Main text

47 Oceanic islands have attracted enormous interest in biogeography ${ }^{4,5}$ and serve as natural

48 laboratories to study the assembly of floras and faunas ${ }^{6,7}$. Empirical tests of fundamental

49 concepts in evolution and ecology using islands as model systems ${ }^{2,8}$ assume that the results can

50 be generalised to non-island contexts. Yet, a long-standing paradigm in island biogeography

51 centres on the notion that isolation, as well as geographic and environmental factors linked to the

52 ontogeny of oceanic islands, lead to evolutionarily unique ${ }^{9,10}$ and functionally distinct biotas $^{11}$.

53 These assumptions raise the question of how functionally distinct oceanic islands can be

54 compared to other systems.

56 In contrast to neutral theories, such as the theory of island biogeography ${ }^{8}$, where all arriving

57 species have the same chance to colonise an island irrespective of their traits, a trait-based

58 perspective leverages differences in ecological strategies among species determined by

59 functional traits to disentangle the processes and identify the mechanisms that have shaped island

60 biotas $^{3,12}$. In functional ecology and functional island biogeography ${ }^{12,13}$, functional differences

61 among species are quantified using morphological and physiological characteristics that impact

62 how plants respond to environmental factors, affect other trophic levels, and influence ecosystem

63 properties ${ }^{14,15}$. Trait syndromes and trade-offs among individual traits reflect fundamental

64 ecological strategies that structure plant life from individuals to communities. This includes the

65 conservative-acquisitive continuum captured by the leaf economics spectrum ${ }^{16,17}$ and the size

66 continuum (stature of whole plants and seed mass), which together, define essential dimensions

67 of functional diversity in vascular plants (e.g., the global spectrum of plant form and function, 
$\left.68 s e n s u^{18}\right)$. Functional traits are also used to estimate functional diversity ${ }^{19}$, which quantifies the

69 diversity and distribution of ecological strategies in a community ${ }^{20}$ and may help identifying the

70 factors that shape an assemblage, such as abiotic conditions ${ }^{21,22}$ or dispersal filters ${ }^{10}$. Ecological,

71 biogeographical, and evolutionary forces may either expand or constrain trait space, thereby

72 driving functional divergence or convergence ${ }^{23}$. However, shortfalls in trait and distribution

73 data ${ }^{24,25}$ usually restrict the geographic extent, spatial grain, and taxonomic coverage of such

74 studies, leading to an incomplete and potentially biased understanding of the factors that

75 underpin a complete flora.

77 Crossing large expanses of ocean and adapting to island environments represents a considerable 78 challenge for plants, likely filtering species with trait values that enhance dispersal and 79 establishment $^{10}$ (but see $^{26}$ ). Moreover, the highly heterogeneous environments ${ }^{27}$ of oceanic 80 islands create ecological opportunities (i.e., empty niche spaces) ${ }^{9}$ that should promote divergence 81 of new trait combinations. Biogeographical processes, such as long-distance dispersal, are thus

82 expected to strongly constrain an island trait space, leading to functional convergence, where

83 species share similar trait combinations. In contrast, evolutionary events, such as speciation via

84 lineage splitting (cladogenesis ${ }^{28}$ ) or via gradual evolution of species (i.e., anagenesis ${ }^{29}$ ) are

85 expected to expand trait space $^{30}$ by generating novel trait combinations that facilitate the 86 occupation of untapped trait space. The Hawaiian silverswords and the Macaronesian Echium

87 alliance are iconic examples of adaptive radiations involving dramatic morphological shifts ${ }^{31,32}$,

88 yet, the relative importance of biogeographical and evolutionary processes in shaping trait

89 diversity and ecological strategies on oceanic islands remains elusive. 
91 Here, we study the flora of Tenerife (Canary Islands, Spain), an oceanic island located in

92 Macaronesian meta-archipelago and an ideal natural laboratory ${ }^{33}$ to test how biogeography and

93 evolution affect island functional diversity. Tenerife exhibits stunning environmental gradients

94 from arid coastal succulent scrub vegetation, to humid laurel forests and alpine vegetation ${ }^{34}$ and

95 contains spectacular examples of insular radiations ${ }^{33}$. Tenerife's flora is well-studied and

96 comprises 436 native seed plants ${ }^{35}$. We measured eight plant functional traits of $80 \%$ of the

97 native seed plants (Fig. 1 and Fig. 2a) to explore matches and mismatches in trait syndromes

98 between Tenerife's native flora and the global spectrum in plant form and function ${ }^{18}$ (Fig. 1). We

99 evaluate how biogeographical and evolutionary processes have shaped the functional diversity of

100 Tenerife's flora by assessing the contribution of five species groups, which are associated with

101 different dispersal and speciation mechanisms, to the overall island trait space (Fig. 2b-f): (i)

102 non-endemic native species, which represent species that colonised the Canaries via long-

103 distance dispersal without undergoing subsequent speciation ${ }^{36}$, (ii) Macaronesian endemics,

104 which signal 'relictualization', a process that results from the survival of species on islands after

105 the extinction of mainland populations, as well as speciation ${ }^{37,38}$, (iii) Canary Islands endemics,

106 which represent both speciation and inter-island dispersal across the archipelago, (iv) Tenerife

107 endemics, which represent in-situ speciation and intra-island dispersal. As a fifth group, we also

108 considered (v) cladogenetic species, which is composed of immigrant lineages that diversified

109 within the Macaronesian meta-archipelago.

111 An oceanic island flora faces similar functional constraints as other floras across the globe.

112 Comparing the variation of traits in the flora of Tenerife with the global spectrum of plant form 113 and function ${ }^{18}$ (Fig. 1 and Extended Data Fig. 1), we find a considerable overlap between the 
114 island and the global trait space (Sørensen similarity coefficient $=0.69$, based on hypervolume

115 overlap for both trait spaces). This suggests that plants on Tenerife largely experience similar

116 constraints as plants in continental floras. However, the density distribution of Tenerife's trait

117 space deviates strikingly from the global one along the first trait space dimension (Fig. 1). The

118 majority of island species are located between the two global functional hotspots, i.e., small

119 statured, light-seeded herbaceous plants and tall, heavy-seeded trees. The position of Tenerife's

120 plants in relation to the global trait space indicates the dominance of shrubs and an

121 underrepresentation of both small herbs and tall trees on the island (Fig. 1 and 2a). Most of

122 Tenerife's plants have a small to intermediate stature (average plant height $=2 \mathrm{~m}$ ), moderate

123 stem density (stem specific density average $=0.5 \mathrm{mg} \mathrm{mm}^{-3}$ ), light seeds (seed mass average $=19$

$124 \mathrm{mg}$ ), and leaves with intermediate size, leaf mass per area (LMA) and nitrogen content (average

125 of leaf area $=3.436 \mathrm{~mm}^{2}, \mathrm{LMA}=93 \mathrm{~g} \mathrm{~m}^{-2}$ and leaf nitrogen $=19 \mathrm{mg} \mathrm{g}^{-1}$, respectively) (Extended

126 Data Fig. 3a).

127

128 Tenerife's Mediterranean climate, marked by seasonal summer droughts and high aridity at low

129 and high elevations, favours shrubs ${ }^{39,40}$. Major aridification across the Canary Islands started 7

130 million years ago and thus coincides with the emergence of a large proportion of insular shrubby

131 plants $\left(80 \%\right.$ of insular lineages on the Canary Islands are woody $\left.{ }^{40,41}\right)$. The higher stem specific

132 density of shrubs compared to herbaceous species decreases the risk of hydraulic failure ${ }^{41,42}$.

133 Succulence represents another key adaptation to the arid environments and this trait is also well

134 represented on the Canary Islands ${ }^{43}$, and this is here captured by leaf thickness. Including Leaf

135 thickness into the trait space (Fig. 2a) highlights the importance of succulence in response to

136 aridity. 
137 The dominance of shrubby species on Tenerife is consistent with the idea that small herbaceous

138 colonisers gradually evolve into taller plants with increased stem density to avoid competition

139 with other species ${ }^{44}$. Yet, the evolution of several Tenerife shrub species and the subsequent

140 increase in shrubbiness has mostly occurred in steep canyons and high-elevation ecosystems ${ }^{45}$,

141 where conditions are unfavourable for trees and competition with taller plants is low. The

142 underrepresentation of tall plants in Tenerife's trait space reflects the comparatively low number

143 of tree species (mainly in laurel and pine forest, and thermophilous woodland ecosystems)

144 compared to shrubs. Overall, the functional dominance of shrubs in the flora of Tenerife is

145 evidence of shrubbiness as a general island syndrome.

147 Biogeography and evolution have jointly shaped island plant trait space. We analysed the 148 relationship of eight plant functional traits (Fig. 2a and Extended Data Fig. 2) for the five species 149 groups (Fig. 2b-f) and found that trait spaces of almost all groups were highly aggregated in the 150 centre of the island trait space. The trait space of non-endemic natives (Fig. 2b), encompasses a 151 large range of trait combinations, which relative to other groups, are evenly distributed across the 152 island trait space, i.e., from light-seeded, short plants to tall plants with heavy seeds (ranging 153 from 0.01 - $230 \mathrm{mg}$ seed mass and 0.1 - $20 \mathrm{~m}$ plant height). Canary endemic species (Fig. 2d)

154 also have a large range of trait combinations, but the trait space is highly dominated by shrubs 155 and extends towards species with high leaf thickness, a trait associated with drought tolerance, 156 and towards species with nitrogen rich leaves. The trait space of Canary endemics also extends 157 towards species with contrasting trait combinations, i.e., low leaf thickness and low leaf nitrogen 158 content, that are consistent with a conservative life strategy. The trait space of Tenerife endemics 159 (Fig. 2e) is mainly dominated by shrubs and succulent species. In contrast, the trait space of 
160 Macaronesian endemics (Fig. 2c) has a bimodal distribution associated with the prevalence of

161 both shrubs and trees. Trait combinations of tree species within the Macaronesian endemics, e.g.,

162 Laurus novocanariensis with its large stature and seed mass (25 m and $600 \mathrm{mg}$, respectively),

163 have not emerged from in-situ speciation but rather from the relictualization of laurel forests, an

164 ecosystem that is largely extinct on the mainland ${ }^{38}$. Lastly, cladogenetic species (Fig. 2f) occur

165 also in the centre of the island trait space, with most species having intermediate stature, light

166 seeds, and thick leaves with low leaf dry matter content (typical for succulents). Trait spaces of

167 cladogenetic species and Tenerife endemics are similar, as most Tenerife endemics emerged via

168 cladogenesis.

169

170 Biogeography and evolution leave imprints on island functional diversity. To capture

171 different aspects of trait distributions among all five groups, we calculated three components of

172 functional diversity: functional richness, functional evenness and functional dispersion ${ }^{23}$ (Fig. 3).

173 Further, we assessed the contribution, i.e., whether a group increases island trait space or not,

174 and the uniqueness of each group within the island trait space by calculating functional

175 contribution and originality ${ }^{23}$ (Extended Data Fig. 4).

177 We found that functional richness (Fig. 3), i.e., the total amount of trait space ${ }^{20}$, and functional

178 dispersion (Fig. 3), i.e., the functional divergence or convergence of species within a trait space,

179 exhibit a similar pattern among groups and are highest for Canary endemics. This result, together

180 with the significant functional contribution and originality of the Canary endemics (Extended

181 Data Fig. 4), indicates that this group possesses unique trait combinations and causes an

182 expansion of the trait space of Tenerife. In contrast, we found that Tenerife endemics have the 
183 lowest functional richness and dispersion among all groups (Fig. 3). This contrasting pattern

184 emerges because several Canary endemics occupy the margins of the trait space (i.e., small

185 herbs, tall shrubs and trees), whereas Tenerife endemics are mainly found in the centre of island

186 trait space (i.e., shrubs and small succulents) (Fig. 2 and Fig. 3). Canary endemic species at the

187 margins of Tenerife's trait space, such as Spartocytisus supranubius, a 4-metre-tall shrub with

188 dense stems (stem specific density $=0.7 \mathrm{mg} \mathrm{mm}^{-3}$ ) or Monanthes laxiflora, a small succulent $(0.2$

$189 \mathrm{~m}$ tall and $0.4 \mathrm{~mm}$ thick leaves), are examples of species with unique trait combinations that

190 expand the island trait space. The high functional diversity of Canary endemics is consistent with

191 the idea that insular species evolve new morphological characteristics to take advantage of

192 unoccupied niche space, thereby avoiding interspecific competition ${ }^{46}$. The high habitat diversity

193 of the Canary Islands provides ample opportunities for species that, together with inter-island

194 dispersal, promotes speciation and drives the high functional diversity of the Canary endemics.

195 Conversely, Tenerife endemics are functionally quite similar; these species occupy similar island

196 habitats, have a low degree of niche differentiation, and have likely emerged via allopatric

197 speciation $^{45}$.

199 Functional evenness (Fig. 3), i.e., the regularity of species' distribution across trait space was

200 highest for Macaronesian endemics and non-endemic natives. The high evenness values for these

201 groups indicate that species are equally distributed among trees, shrubs, and herbs. Further, the

202 high functional contribution and functional originality of Macaronesian endemics (Extended

203 Data Fig. 4) illustrates that certain species and relictualization events may contribute

204 disproportionately to island trait space by adding unique trait combinations. 
Unexpectedly, we found that cladogenetic species did not expand the trait space of Tenerife (cf. intermediate functional richness and dispersion values in Fig. 3). We attribute this result to a

207 greater frequency of non-adaptive speciation events relative to adaptive ones ${ }^{47}$. Unlike adaptive

208 radiations, where species commonly adapt trait values to cope with changing environmental 209 conditions $^{32}$, non-adaptive radiations ${ }^{47}$ may not result in shifts in trait values because

210 environmental conditions may be similar between isolated populations. This leads to newly

211 evolved species that are functionally similar to ancestral species. Further, the uneven trait space

212 of cladogenetic species (cf. low functional evenness values in Fig. 3) is consistent with the idea

213 that environmental filters result in convergence around similar trait combinations ${ }^{48}$. The

214 aridification of the Canary Islands created new habitats, yet the harsh environmental conditions

215 of these habitats limit viable trait combinations ${ }^{49}$. Lastly, non-endemic native species had high

216 functional richness and dispersion values across groups (Fig. 3). Contrary to our expectation, this

217 result suggests that long-distance dispersal is contributing to functional diversity rather than 218 constraining it.

220 How radiated lineages contribute to the island functional trait space. To understand how

221 speciation due to radiations has shaped the functional trait space of Tenerife, we quantified the

222 functional contribution and originality of the 21 major lineages (i.e., 161 species, cf. Extended

223 Data Fig. 5-6), which have radiated in Macaronesia and are present on the Canary Islands and

224 Tenerife, to the island trait space. We found that the most diverse radiated lineages, Aeonium

225 (>30 species) and Polycarpaea lineage (7 species), contributed significantly to the expansion of

226 Tenerife trait space. Both lineages expand the trait space towards small plants with thick leaves

227 (Extended Data Fig. 5c). In contrast, the vast majority of radiated lineages did not increase island 
228 trait space. This result suggests that species within the Aeonium and Polycarpaea lineages

229 evolved trait combinations including succulent leaves and remarkable size changes that allow

230 them to exploit available niche space across a variety of habitats. The minimal contributions of

231 the other, less diverse radiated lineages to island trait space might indicate that these radiations

232 are to a large degree non-adaptive. Yet, it could also indicate that while the newly evolved

233 species are similar to those of co-occurring species, they may have evolved other traits not

234 measured in this study that enable them to exploit empty niche space.

235

236 We conclude that evolution via different speciation pathways (i.e., anagenesis and cladogenesis)

237 at the archipelago level, together with biogeographical processes such as relictualization and

238 inter-island dispersal at the archipelago or meta-archipelago level, have jointly shaped the trait

239 space of Tenerife. Contrary to our hypothesis, cladogenesis has led to functional convergence,

240 and therefore only marginally to increases functional diversity. The predominance of shrubbiness

241 and leaf succulence across the island flora additionally reflects a strong imprint of environmental

242 filtering acting on the trait space of Tenerife. Overall, our results show how functional diversity

243 of an oceanic island flora emerges from the interaction among biogeographical, ecological and

244 evolutionary processes. Our approach offers a first step towards understanding, from a trait-

245 based perspective, the assembly of an entire native flora. 


\section{References}

248 1. Carlquist, S. The biota of long-distance dispersal. II. Loss of dispersibility in Pacific 249 Compositae. Evolution. 20, 30-48 (1966).

$2502 . \quad$ Darwin, C. On the Origin of Species. (Murray, London, 1859).

251 3. Burns, K. C. Evolution in isolation: the search for an island syndrome in plants. 252 (Cambridge University Press, 2019).

253 4. Patiño, J. et al. A roadmap for island biology: 50 fundamental questions after 50 years of The Theory of Island Biogeography. J. Biogeogr. 44, 963-983 (2017).

255 5. Whittaker, R. J., Fernández-Palacios, J. M., Matthews, T. J., Borregaard, M. K. \&

Triantis, K. A. Island biogeography: Taking the long view of nature's laboratories.

258 6. Losos, J. B. \& Ricklefs, R. E. Adaptation and diversification on islands. Nature 457, 830$259836(2009)$.

260 7. Craven, D., Knight, T. M., Barton, K. E., Bialic-Murphy, L. \& Chase, J. M. Dissecting macroecological and macroevolutionary patterns of forest biodiversity across the Hawaiian archipelago. Proc. Natl. Acad. Sci. 116, 16436-16441 (2019).

263 8. MacArthur, R. H. \& Wilson, E. O. The Theory of Island Biogeography. The Journal of 264 Wildlife Management vol. 33 (Princeton, NJ: Princeton University Press, 1969).

2659 9. Gillespie, R. G. \& Baldwin, B. G. 'Island biogeography of remote archipelagoes.' The theory of island biogeography revisited. Princeton University Press (2010).

267 10. Weigelt, P. et al. Global patterns and drivers of phylogenetic structure in island floras. Sci. Rep. 5, 1-13 (2015)

269 11. Loiseau, N. et al. Global distribution and conservation status of ecologically rare mammal 
and bird species. Nat. Commun. 11, 5071 (2020).

271 12. Schrader, J., Wright, I. J., Kreft, H. \& Westoby, M. A roadmap to plant functional island biogeography. Biol. Rev. 96, 2851-2870 (2021).

273 13. Violle, C., Reich, P. B., Pacala, S. W., Enquist, B. J. \& Kattge, J. The emergence and (2014).

276 14. Lavorel, S. \& Garnier, E. Predicting changes in community composition and ecosystem functioning from plant traits: Revisiting the Holy Grail. Funct. Ecol. 16, 545-556 (2002).

278 15. Violle, C. et al. Let the concept of trait be functional! Oikos 116, 882-892 (2007).

279 16. Wright, I. J. et al. The worldwide leaf economics spectrum. Nature (2004) 280 doi:10.1038/nature02403.

281 17. Reich, P. B. The world-wide 'fast-slow' plant economics spectrum: A traits manifesto. $J$. Ecol. 102, 275-301 (2014).

283 18. Díaz, S. et al. The global spectrum of plant form and function. Nature 529, 167-171 (2016).

285 19. Díaz, S. \& Cabido, M. Vive la différence: Plant functional diversity matters to ecosystem processes. Trends Ecol. Evol. 16, 646-655 (2001).

287 20. Mouchet, M. A., Villéger, S., Mason, N. W. H. \& Mouillot, D. Functional diversity measures: An overview of their redundancy and their ability to discriminate community assembly rules. Funct. Ecol. 24, 867-876 (2010).

290 21. Wieczynski, D. J. et al. Climate shapes and shifts functional biodiversity in forests worldwide. Proc. Natl. Acad. Sci. 116, 7591-7591 (2019).

292 22. Bruelheide, H. et al. Global trait-environment relationships of plant communities. Nat. 
Ecol. Evol. 2, 1906-1917 (2018).

294 23. Mammola, S. \& Cardoso, P. Functional diversity metrics using kernel density n -dimensional hypervolumes. Methods Ecol. Evol. 11, 986-995 (2020).

296 24. König, C. et al. Biodiversity data integration-the significance of data resolution and 297 domain. PLoS Biol. 17, 1-16 (2019).

298 25. Cornwell, W. K., Pearse, W. D., Dalrymple, R. L. \& Zanne, A. E. What we (don't) know about global plant diversity. Ecography (Cop.). 42, 1819-1831 (2019).

26. Heleno, R. H. \& Vargas, P. How do islands become green? Glob. Ecol. Biogeogr. 24, $518-526(2015)$.

27. Barajas-Barbosa, M. P., Weigelt, P., Borregaard, M. K., Keppel, G. \& Kreft, H. Environmental heterogeneity dynamics drive plant diversity on oceanic islands. $J$. Biogeogr. 47, 2248-2260 (2020).

28. Stuessy, T. \& Crawford, D. J. Patterns of Phylogeny in the Endemic Vascular Flora of the Juan Fernandez Islands, Chile. Am. Soc. Plant Taxon. 15, 338-346 (1990).

29. Stuessy, T. F. et al. Anagenetic evolution in island plants. J. Biogeogr. 33, 1259-1265 (2006).

30. Emerson, B. C. \& Gillespie, R. G. Phylogenetic analysis of community assembly and structure over space and time. Trends Ecol. Evol. 23, 619-630 (2008).

311 31. Bohle, U. R., Hilger, H. H. \& Martin, W. F. Island colonization and evolution of the insular woody habit in Echium L. (Boraginaceae). Proc. Natl. Acad. Sci. 93, 11740-11745

314 32. Givnish, T. J. et al. Origin, adaptive radiation and diversification of the Hawaiian lobeliads (Asterales: Campanulaceae). Proc. R. Soc. B Biol. Sci. 276, 407-416 (2009). 
316 33. Florencio, M. et al. Macaronesia as a Fruitful Arena for Ecology, Evolution, and

317 Conservation Biology. Front. Ecol. Evol. 9, (2021).

318 34. Fernández-Palacios, J. M. Climatic responses of plant species on Tenerife, The Canary

319 Islands. J. Veg. Sci. 3, 595-603 (1992).

320 35. Acebes-Ginovés, J., León Arencibia, M. \& Rodríguez Navarro, M. Lista de especies 321 silvestres de Canarias. Hongos, plantas y animales terrestres 2009. (Santa Cruz de Tenerife: Gobierno de Canarias, 2010).

36. Price, J. P. et al. Colonization and diversification shape species-area relationships in three Macaronesian archipelagos. J. Biogeogr. 45, 2027-2039 (2018).

325 37. De Nascimento, L., Willis, K. J., Fernández-Palacios, J. M., Criado, C. \& Whittaker, R. J. The long-term ecology of the lost forests of la Laguna, Tenerife (Canary Islands). J. Biogeogr. 36, 499-514 (2009).

38. Fernández-Palacios, J. M. et al. A reconstruction of Palaeo-Macaronesia, with particular reference to the long-term biogeography of the Atlantic island laurel forests. J. Biogeogr. 38, 226-246 (2011).

331 39. Carlquist, S. J. Island biology. (Columbia University Press, 1974).

332 40. van Huysduynen, A. et al. Temporal and palaeoclimatic context of the evolution of insular woodiness in the Canary Islands. Ecol. Evol. 11, 12220-12231 (2021).

334 41. Dória, L. C. et al. Insular woody daisies (Argyranthemum, Asteraceae) are more resistant

337 42. Lens, F., Davin, N., Smets, E. \& del Arco, M. Insular Woodiness on the Canary Islands: A 338 Remarkable Case of Convergent Evolution. Int. J. Plant Sci. 174, 992-1013 (2013). 
339 43. Shmida, A. \& Werger, M. J. A. Growth form diversity on the Canary Islands. Vegetatio

$340 \quad \mathbf{1 0 2}, 183-199(1992)$.

341 44. Biddick, M., Hendriks, A. \& Burns, K. C. Plants obey (and disobey) the island rule. Proc.

$342 \quad$ Natl. Acad. Sci. 116, 17632-17634 (2019).

343 45. Fernández-Palacios, J. M. et al. Evolutionary winners are ecological losers among oceanic

344 island plants. J. Biogeogr. 48, 2186-2198 (2021).

345 46. Silvertown, J. The Ghost of Competition Past in the Phylogeny of Island Endemic Plants.

92, 168-173 (2004).

347 47. Rundell, R. J. \& Price, T. D. Adaptive radiation, nonadaptive radiation, ecological speciation and nonecological speciation. Trends Ecol. Evol. 24, 394-399 (2009).

349 48. Spasojevic, M. J. \& Suding, K. N. Inferring community assembly mechanisms from 652-661 (2012).

49. Carvajal-Endara, S., Hendry, A. P., Emery, N. C. \& Davies, T. J. Habitat filtering not dispersal limitation shapes oceanic island floras: species assembly of the Galápagos archipelago. Ecol. Lett. 20, 495-504 (2017). 


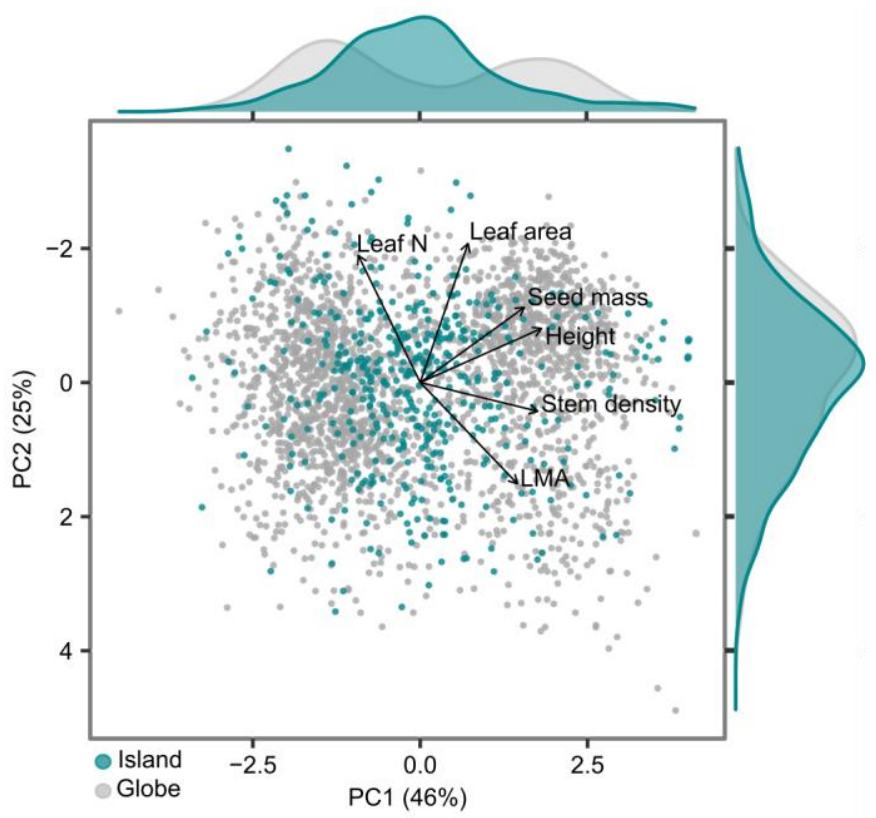

Figure 1. Trait space of the native flora of Tenerife is subject to similar constraints as the

values. Trait space of Tenerife using 436 native seed plant species (turquoise dots) in relation to

364 principal component analysis (PCA; for comparability we inverted the y axis, i.e., PC2) of six the PCA in Extended Data Fig. 1. 
a) Tenerife trait space

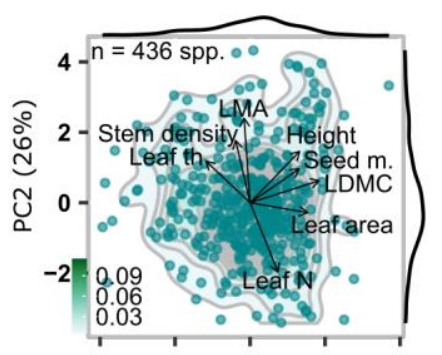

b)

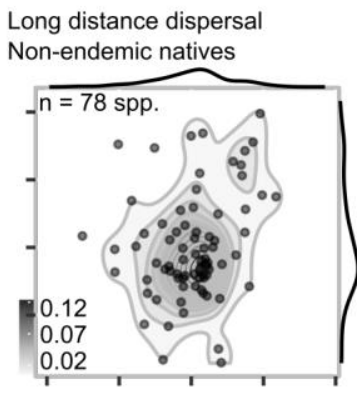

Inter-island dispersal

c) Macaronesian endemics

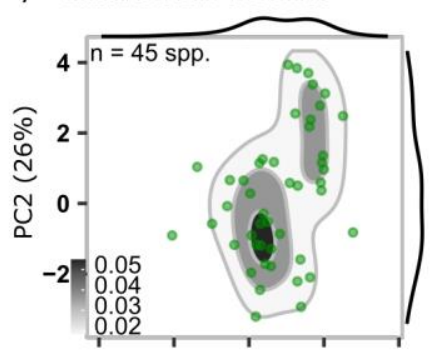

d) Canary endemics

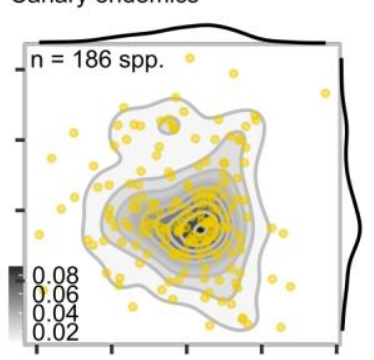

Speciation

e) Tenerife endemics

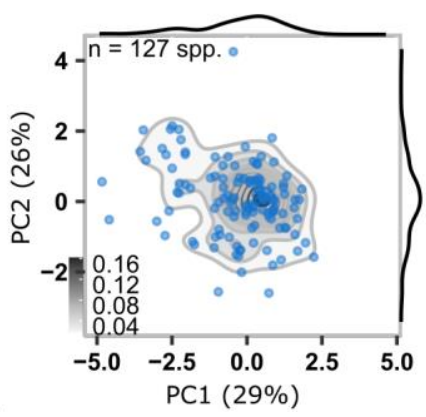

f) Cladogenetic species

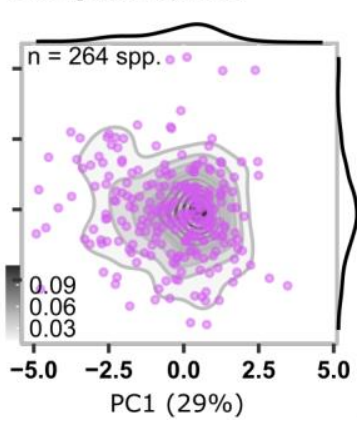

Figure 2. Trait spaces for the native flora of Tenerife(a) and dissected into five distinct species groups (b-f) illustrate how biogeography and evolution shape the functional

374 content (LDMC), leaf mass per area (LMA), Leaf N (leaf Nitrogen content), leaf thickness (Leaf

375 th), stem density (SSD), seed mass (Seed m.), and maximum plant height (Height). Projections

376 are of the two first dimensions of variation from the principal component analysis. Contours are

377 built using 2D kernel density estimation. Gradient legends (bottom-left side) correspond to the

378 proportion of data contained in a contour break. More detail on the PCA in Extended Data Fig. 2. 


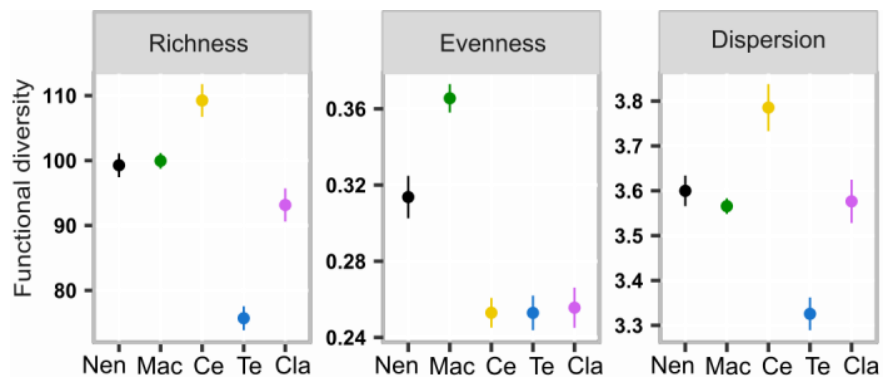

380 Figure 3. Contribution of biogeographical and evolutionary processes to the functional

381 diversity of Tenerife. Functional richness, functional dispersion and functional evenness were

382 calculated using n-dimensional hypervolumes while controlling for the number of species

383 richness per group (see Methods). Different colours refer to a species group, i.e., black to non-

384 endemic native (Nen), green to Macaronesian endemics (Mac), yellow to Canary endemics (Ce),

385 blue to Tenerife endemics (Te) and purple to cladogenetic species (Cla). Dots and error bars

386 correspond to the mean values and $95 \%$ confidence intervals, based on species-richness based

387 rarefaction values. 


\section{Methods}

391 Tenerife as a model system. Tenerife is the largest $\left(2058 \mathrm{~km}^{2}\right)$ and tallest $(3715 \mathrm{~m}$ a.s.1.) of the

392 Canary Islands, an archipelago that belongs to the meta-archipelago Macaronesia, a floristic

393 region off the coast of Northern Africa and Western Europe in the Atlantic Ocean ${ }^{33}$. The island is

394 of volcanic origin and its oldest substrate is about 8 million years old ${ }^{50}$. Due to its complex

395 topography, dynamic geological history ${ }^{50}$, and interaction with the north-eastern trade wind

396 system, Tenerife has a very high environmental heterogeneity and a wide range of different

397 ecozones and habitats ${ }^{51}$.

399 Floristic and biogeographical data. We analysed all native seed plant species of Tenerife as

400 listed in the latest version of the vascular plant species checklist of the Canary Islands ${ }^{35}$. Since

401 the native status of several Canary Islands species remains unresolved ${ }^{36}$, we included only 402 species categorised as native (i.e., "nativa segura" status from the Canary Islands plant 403 checklist), yielding a total of 436 species $^{35}$. We classified species into five different groups 404 according to species endemism status from the checklist ${ }^{35}$ as follows: non-endemic native (78 405 species), Macaronesian endemics (45 species), Canary Islands endemics (186 species) and 406 endemics to Tenerife (127 species). The cladogenetic species group (264 species) is composed of 40721 lineages that have radiated across the Canary Islands and Macaronesia and have produced 408 more than three extant species (according to ${ }^{36}$ ); therefore, this group contains Macaronesian, 409 Canary as well as Tenerife endemics. 
411 Trait sampling and measurement. We collected and measured leaf and stems traits ${ }^{16,18}$ for $79 \%$

412 and $76 \%$ respectively, of all Tenerife native seed plants (344 and 330 species): leaf area $\left(\mathrm{mm}^{2}\right)$

413 as the one-side surface area of the individual lamina, leaf dry matter content (LDMC; $\mathrm{mg} \mathrm{g}^{-1}$ ) as

414 the leaf dry mass per unit of water-saturated fresh mass, leaf mass per area (LMA; $\left.\mathrm{g} \mathrm{m}^{-2}\right)$ as the

415 leaf dry mass per unit of lamina surface area, leaf Nitrogen content (Leaf $\mathrm{N}_{\mathrm{s}} ; \mathrm{mg} \mathrm{g}^{-1}$ ) as the

416 nitrogen content per unit of lamina dry mass, leaf thickness (Leaf th; $\mathrm{mm}$ ), stem specific density

417 (Stem density; $\mathrm{mg} \mathrm{mm}^{-3}$ ) as dry mass per unit of fresh stem volume. We sampled plants across

418 the entire island at more than 500 locations (Extended Data Fig. 7), covering the full range of

419 elevational and climatic gradients of Tenerife from sea level to $2700 \mathrm{~m}$ a.s.l. We sampled rare

420 species (when possible) at only one site for conservation reasons and a few rare species $(n=20)$

421 in botanical gardens ${ }^{52}$ (Jardín de Aclimatación de La Orotava and Jardines Campus Universidad

422 de La Laguna in Tenerife, and Jardín Botánico Canario Viera y Clavijo in Gran Canaria). We

423 confirmed species identity with botanical experts, Rüdiger Otto and Rubén Barone, and

424 identification books ${ }^{53}$. We collected three replicates (individuals per species) for $60 \%$ of all 361

425 sampled species, one to two replicates for $16 \%$, and four to five replicates for $6 \%$ of all the

426 sampled species.

428 Trait values for leaves, stems and seeds were measured following standardised protocols ${ }^{54}$. We 429 collected healthy, fully expanded sun leaves from individual plants. Depending on leaf size, we

430 collected between 10 (for $>1 \mathrm{~cm}^{2}$ leaves) to 100 (for $<1 \mathrm{~cm}^{2}$ leaves) leaves per individual. To 431 measure stem traits and ensure that plants were not damaged, we collected samples from the first 432 adjacent branch of the main plant stem, when plants were shrubs. For small herbs and vines, we 433 collected the plant organ acting as a stem. To sample the stem density of trees, we used an 
434 increment borer, to extract a wood core from the bark inward (10 mm diameter core taken at $\sim 1.2$

$435 \mathrm{~m}$ above ground). We stored the fresh plant material in coolers to prevent dehydration and

436 measured fresh leaf mass using an analytical balance (0.01 mg precision from PCB 2500-2 Kern

$437 \&$ Sohn) within 24 hours after collection. Leaf thickness and leaf area (leaves smaller than $1 \mathrm{~cm}^{2}$

438 were scanned at $600 \mathrm{dpi}$ and leaves larger than $1 \mathrm{~cm}^{2}$ at $300 \mathrm{dpi}$ ) were also measured within 24

439 hours after collection. Leaf area was calculated using WinFOLIA software (Version 2016b Pro,

440 Regent Instruments Canada, 2016). To measure the volume of fresh stems, we first measured

441 their length and diameter with a digital calliper. As stems are not perfect cylinders, we measured

442 diameter in three different stem sections and used the mean value per stem. We computed fresh

443 stem volume using the following formula for cylinders: $\mathrm{V}=\Pi \mathrm{r}^{2} \mathrm{~h}$, where $\Pi$ is the constant $\mathrm{Pi}, \mathrm{r}$ is

444 radio, and $\mathrm{h}$ is height. We oven dried leaves and stems for 48 hours, or until a stable weight was

445 reached, at $80^{\circ} \mathrm{C}$ and then measured leaf and stem dry mass using the same analytical balance.

446 Nitrogen content of the dry leaves was determined by a $\mathrm{C} / \mathrm{N}$ elemental analyser (Vario EL III,

447 elementar, Hanau, Germany).

449 We measured seed mass ( $\mathrm{mg}$ ) for $74 \%$ (322 species) of all native seed plants of Tenerife as the

450 dried mass of an individual seed in the field (9 species) and at the seed bank from the Jardín

451 Botánico Canario "Viera y Clavijo" in Gran Canaria (313 species). We counted between 5 to 200

452 seeds per species and weighed them using an analytical balance (0.001 mg precision). We

453 obtained individual seed mass by dividing the total mass of the seeds by the number of seeds. For

454 very small seeds $(<0.1 \mathrm{~mm})$, we calculated seed mass using a test tube containing a volume of

455 seeds for which the seed count was known. We obtained maximum plant height (Height; m), 
which is the upper boundary of the main photosynthetic tissue at maturity in metres, for $97 \%$ of

457 all native species of Tenerife from the literature ${ }^{53}$.

459 Prior to analysis, we inspected the density distribution of single traits and correlations among

460 traits (Extended Data Fig. 3). We then used phylogenetic trait imputation to estimate missing

461 trait values. We imputed trait values for $20 \%$ of leaf trait values, $27 \%$ of stem density, $26 \%$ of

462 seed mass, and 3\% of maximum plant height. We followed the phylogenetic imputation

463 procedure suggested by ${ }^{55}$. To this end, we first constructed the phylogeny using the mega-

464 phylogeny ${ }^{56}$ and conservatively bound species to the backbone using dating information from

465 congeners in the tree with the 'congeneric.merge' function in package 'pez' ${ }^{57}$ implemented for R

466 software ${ }^{58}$. After checking for synonyms, we bound 430 species to the phylogeny. We used a

467 random forest algorithm using the 'missForest' function from the MissForest $\mathrm{R}$ package ${ }^{59}$ to

468 predict missing trait values for the 430 species (see density distribution of original and imputed

469 trait values in Extended Data Fig. 3b). We filled in the missing six species trait values using the

470 results of a naive prediction without phylogenetic information, and which used the random forest

471 algorithm. Using out-of-bag error, we measured the prediction error of the random forest

472 algorithm that included phylogenetic relationships among species against naive predictions. We

473 found that phylogenetically informed imputation performed better than the naive imputation for 474 nearly all traits (Extended Data Table 1).

476 Global trait data. For comparison of the Tenerife trait space and the global traits space, we used

477 the global trait data from ${ }^{18}$, which has complete information for six plant traits (Leaf area, LMA, 478 Leaf N, Seed mass, Stem density and Height) for 2213 plant species. Before comparison among 
479 Tenerife and global trait space, we removed 14 species from the global trait data that belonged to

480 the flora of Tenerife. We compared 2199 species from the global trait data with 436 Tenerife

481 species.

482

483 Functional trait space. We performed a principal component analysis (PCA) on the log- and z-

484 transformed (centred and rescaled to unit variance) mean trait values. For the comparison of

485 Tenerife versus global trait space of plant form and function (Fig. 2), we used only six plant

486 functional traits: leaf area, LMA, leaf N, seed mass, stem density and height. For the trait space

487 analysis of Tenerife island and the different biogeographical groups (Fig. 3a and Extended Data

488 Fig. 2), we used eight plant functional traits: leaf area, LMA, LDMC, leaf N, leaf th, seed mass,

489 stem density and height. We visualised the trait space of each group based on the eight plant

490 traits (Fig. 3).

491

492 Functional diversity. We calculated three components of functional diversity (Fig. 3) using the

493 n-dimensional functional hypervolumes by ${ }^{60}$. This approach to functional diversity is thought to

494 be more accurate than traditional approaches because it accounts for gaps in trait space and, in

495 doing so, avoids overestimation of functional diversity. To compute hypervolumes, we used a

496 fixed kernel bandwidth for all groups using the 'estimate_bandwidth' (using cross-validation as

497 kernel estimator method) function in the $\mathrm{R}$ package Hypervolume ${ }^{61}$. We used the Gaussian

498 method to build hypervolumes, as it is the least sensitive method to variation in bandwidth and

499 fits the data loosely, which is suitable for functional diversity and fundamental niche modelling

500 applications $^{60}$. Using the hypervolumes, we then calculated functional richness, evenness and

501 dispersion using the function 'kernel.alpha', 'kernel.evenness', and 'kernel.dispersion' in the R 
502 package $\mathrm{BAT}^{23}$. Functional richness is the total volume of a trait space. Functional dispersion

503 quantifies how spread or dense a given trait space is, by calculating the average difference

504 between the trait space centroid and random points (i.e., randomly placed species) within the

505 boundaries of the hypervolume ${ }^{23}$. Functional evenness quantifies how regular a given trait space

506 is, by calculating the overlap between the observed hypervolume and a theoretical, perfectly

507 even hypervolume ${ }^{23}$. Sørensen (volume of the intersection of island trait space and global trait

508 space, divided by the volume of union of island trait space and global trait space) similarity

509 coefficients (cf. Fig. 2), by first building Gaussian hypervolumes with a fixed bandwidth, for

510 both global and island data and then computed hypervolume overlap statistics, using the

511 'hypervolume_overlap_statistics' function from the R package Hypervolume ${ }^{60}$. To estimate the

512 contribution (whether a group increases island trait space or not) and originality (a group with

513 high originality value has a unique within the island trait space, which translates into unique trait

514 combinations relative to the island) of the five groups to the island trait space, we first calculated

515 functional contribution ${ }^{23}$ as the net contribution of each single species to the total island

516 hypervolume, and functional originality ${ }^{23}$, as the average dissimilarity difference between a

517 given species and a sample of random points (10\% of the total random points) within the

518 boundaries of the island hypervolume ${ }^{23}$. To assess the functional contribution and originality of

519 each group, we plotted the functional contribution and functional originality values per of the

520 species belonging to a given group against all other species that do not belong to the group as

521 box plots (Extended Data Fig. 4).

523 Data analysis. We used Kruskal-Wallis tests to assess differences among the first and second

524 principal components of the trait spaces of each group (Extended Data Fig. 2c), as well as for 
525 assessing the statistical significance of functional contribution and originality of each group

526 (Extended Data Fig. 4) and 21 radiated lineages (Extended Data Fig. 5 and Extended data Table

527 2) to the island trait space. For the test, we used the 'kruskal' function in the R package

528 Agricolae $^{62}$. Because functional diversity metrics are commonly affected by the number of

529 species $^{63}$, we performed species-richness based rarefaction to ensure that values were

530 comparable across the five groups. To this end, we selected a minimum common number of

531 species $(n=30)$ across the five groups, which we randomly sampled 99 times with replacement,

532 and calculated the functional diversity metrics each time per group. We computed mean values

533 and $95 \%$ confidence intervals from all samples to compare functional diversity metrics across

534 groups (Fig. 3). Lastly, we visualised the functional trait spaces (Fig. 2) using the

535 'stat_density_2d' function in the R package ggplot ${ }^{64}$. We performed all statistical analysis and

536 data visualisation using $\mathrm{R}$ software version 4.1.0.

538 Data Availability

539 The trait data and floristic information of the species that support the findings of this study are

540 available in Figshare repository https://figshare.com/s/a9d343529990afa0c799

\section{Code Availability}

543 The analysis and data visualisation performed in $\mathrm{R}$ software that support the findings of this

544 study are available in Figshare repository https://igshare.com/s/a9d343529990afa0c799 


\section{Methods references}

547 50. Troll, V. R. \& Carracedo, J. C. The Geology of Tenerife. in The Geology of the Canary Islands 227-355 (Elsevier, 2016).

549 51. Fernández-Palacios, J. M. \& Nicolás, J. P. Altitudinal pattern of vegetation variation on Tenerife. J. Veg. Sci. (1995).

551 52. Perez, T. M. et al. Botanic gardens are an untapped resource for studying the functional ecology of tropical plants. Philos. Trans. R. Soc. B Biol. Sci. 374, 20170390 (2019).

53. Muer, T., Sauerbier, H. \& Calixto, F. C. Die Farn-und Blütenpflanzen der Kanarischen Inseln. (Margraf Publishers GmbH, 2016).

54. Pérez-Harguindeguy, N. et al. Corrigendum to: New handbook for standardised measurement of plant functional traits worldwide. Aust. J. Bot. 64, 715 (2016).

557 55. Penone, C. et al. Imputation of missing data in life-history trait datasets: which approach performs the best? Methods Ecol. Evol. 5, 961-970 (2014).

559 56. Smith, S. A. \& Brown, J. W. Constructing a broadly inclusive seed plant phylogeny. Am. J. Bot. 105, 302-314 (2018).

561 57. Pearse, W. D. et al. An introduction to pez. https://cran.r-project.org/web/packages/pez/ (2021).

563 58. R Core Team. R: A language and environment for statistical computing. R Foundation for Statistical Computing, Vienna, Austria. (2021).

565 59. Stekhoven, D. J. \& Bühlmann, P. missForest: Nonparametric Missing Value Imputation using Random Forest $R$ package version 1.3. https://cran.rproject.org/web/packages/missForest/index.html (2013).

568 60. Blonder, B. Hypervolume concepts in niche- and trait-based ecology. Ecography. 41, 
bioRxiv preprint doi: https://doi org/10.1101/2022 03.04 482684; this version posted March 5, 2022. The copyright holder for this preprint (which was not certified by peer review) is the author/funder, who has granted bioRxiv a license to display the preprint in perpetuity. It is made available under aCC-BY-NC 4.0 International license.

$1441-1455$ (2018).

570 61. Blonder, B. R Pakcage: Hypervolume: High Dimensional Geometry and Set Operations Using Kernel Density Estimation, Support Vector Machines, and Convex Hulls. https://cran.r-project.org/web/packages/hypervolume/ (2021).

573 62. De Mendiburu, F. Agricolae: statistical procedures for agricultural research. $R$ package version, 1(1), 1-4. https://cran.r-project.org/web/packages/agricolae/ (2021).

575 63. Schleuter, D., Daufresne, M., Massol, F. \& Argillier, C. A user's guide to functional diversity indices. Ecol. Monogr. 80, 469-484 (2010).

577 64. Wickham, H. ggplot2: elegant graphics for data analysis. Springer-Verlag (2016). 


\section{Acknowledgements}

580 M.P.B.B. and H.K. acknowledge funding from the German Research Foundation (DFG)

581 Research Training Group 1644 'Scaling Problems in Statistics', grant no. 152112243. D.C.

582 acknowledges funding from the Agencia Nacional de Investigación y Desarrollo (Chile;

583 FONDECYT Regular No 1201347). We thank the Jardín Botánico Canario "Viera y Clavijo" in

584 Gran Canaria for allowing measurements in the seed bank as well as for the samples taken of

585 rare species that were not possible to find in the field. We thank Nora Strassburger, Mercedes

586 Vidal Rodríguez and Arnau Andreu Diez for invaluable assistance in the field and in the

587 laboratory. We also thank Rubén Barone for assisting with plant identification.

\section{Author contributions}

590 H.K. conceived the initial idea. M.P.B.B., D.C., P.W., and H.K. further developed the concepts

591 and designed the research. M.P.B.B. collected and measured plant trait data and performed the 592 analysis. P.D. supported the analysis. R.O. supported plant trait data collection and species 593 identification. All authors contributed to the interpretation of the results and writing of the paper.

\section{Competing interest declaration}

596 The authors declare no competing interests.

598 Correspondence and requests for materials should be addressed to Martha Paola Barajas 599 Barbosa,paolabarajas@gmail.com, paola.barajas@idiv.de. 